\title{
Major B-H Loop Measurement of Toroidal Shape Magnetic Powder Core
}

\author{
Derac Son* \\ Dept. of Photonics and Sensors, Hannam University, Hannamro 70, Daedeok-gu Daejeon 306-791, Korea
}

(Received 9 June 2014, Received in final form 18 June 2014, Accepted 19 June 2014)

\begin{abstract}
Toroidal cores made of metallic powder requires large magnetic field strength up to few decade $\mathrm{kA} / \mathrm{m}$ to obtain major hysteresis loop. To overcome thermal heat generation problem from large exciting current during measurement, we have employed a real time hysteresis loop tracer which can digitize and calculate B-H signals in personal computer as real time. For example, when we magnetize specimen at $10 \mathrm{~Hz}$ frequency, we could display hysteresis loops 10 times per second. Using the real time hysteresis loop tracer, we could measure major hysteresis loop of toroidal shape metallic powder core at maximum flux density or maximum magnetic field strength to be measured within 5 second not to significant increasement of specimen temperature due to the heat dissipation from coil windings. For the constructed hysteresis loop tracer, we could measure hysteresis loop at magnetic field strength higher than $50 \mathrm{kA} / \mathrm{m}$ for the toroidal shape specimen.
\end{abstract}

Keywords : magnetic measurement, toroidal core, magnetic powder core, B-H loop tracer, major hysteresis loop

\section{토로이드형 분말코어의 Major B-H Loop 측정}

\author{
손대락*
}

한남대학교 광센서공학과, 대전시 대덕구 한남로 70번지, 306-791

(2014년 6월 9일 받음, 2014년 6월 18일 최종수정본 받음, 2014년 6월 19일 게재확정)

토로이드 형태의 자성분말합금 코어의 경우 major B-H loop을 측정하기 위해서는 수십 $\mathrm{kA} / \mathrm{m}$ 이상의 높은 자화력을 인가하여 야 한다. 이 경우 측정과정에서 일차코일에 권선된 에나멜 동선에서 발생하는 열 때문에 측정이 매우 어렵다. 본 연구에서는 토 로이드 형태의 자성분말합금 코어 major B-H loop을 직접 측정할 수 있는 장치를 설계 제작하고, 그 성능을 측정하였다. 수십 $\mathrm{kA} / \mathrm{m}$ 이상의 자화력을 인가하기 위하여 최대 전류가 $100 \mathrm{~A}$ 인 전력 증폭기와 측정 시간 중에 높은 전류에 의하여 코일 권선에 서 발생하는 열 문제를 해결하기 위하여 실시간으로 자기 이력 곡선을 측정 할 수 있게 실시간으로 B-H 신호를 디지털신호로 변환하여 컴퓨터 소프트웨어에서 자속밀도 $B$ 와 자화력 $H$ 값을 계산하고, 이 값들로 부터 주요 자기 특성인 최대자속밀도 $B_{\max }$, 최대 자화력 $H_{\max }$, 보자력 $H_{c}$, 잔류자속밀도 $B_{r}$ 및 형상인자 $(\mathrm{FF})$ 를 계산하여 가상계측기 $(\mathrm{VI})$ 창으로 표시 할 수 있게 하였다. 제 작된 장치를 이용하여 외경이 $134 \mathrm{~mm}$, 내경이 $77 \mathrm{~mm}$, 높이가 $42 \mathrm{~mm}$ 인 자성분말코어에 일차 코일을 직경이 $1 \mathrm{~mm}$ 인 에나멜 동 선을 401 회 권선하고 이차 코일을 직경이 $0.2 \mathrm{~mm}$ 인 에나멜 동선 5 회 권선하여 측정을 하여 본 결과 최대 인가 자기장을 $50 \mathrm{kA} /$ $\mathrm{m}$ 까지 인가하면서 자기이력곡선을 측정 할 수 있었다.

주제어 : 자기측정, 토로이드코어, 자성분말코어, 자기이력곡선측정, 주자기이력곡선

I. 서

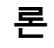

자성분말코어는 분말과 분말사이가 비자성의 부도체인 접 합체로 되어 있고 분말의 직경이 $\mu \mathrm{m}$ 이하로 적기 때문에 교 류 자화과정에서 발생하는 와전류에 의한 손실이 발생되지 않

(C) The Korean Magnetics Society. All rights reserved.

*Corresponding author: Tel: +82-42-629-7512,

Fax: +82-42-629-8313, e-mail: deracson@hnu.kr
기 때문에 고주파용코어로 적절하여 많이 사용되고 있다. 그 러나 분말을 접착시키는 비자성의 부도체인 접착제에 의한 자 기 퍼텐셜(magnetic potential)의 감소로 분말코어를 포화자화 시키는 데는 일반적으로 수십 $\mathrm{kA} / \mathrm{m}$ 이상의 자화력이 필요하 게 된다. 따라서 자성분말 합금으로 된 코어는 $\mathrm{DC}$ bias 전 류에 의해서도 일정한 투자율이 유지되어야 되는 인덕터나 권 선에 의한 손실보다 코어의 의하여 발생하는 철손의 영향이 큰 고주파용 변압기에 주로 사용되고 있다. 
한편 자성분말합금으로 제작된 코어는 대부분 토로이드 형 태로 제작이 되어 있고 측정방법도 측정표준규격에 있다 $[1$, 2]. 그러나 코어의 자기적 특성인 major B-H loop을 측정하 기 위해서는 수십 $\mathrm{kA} / \mathrm{m}$ 의 높은 자화력을 필요로 하기 때문 에 토로이드 코어에 코일을 권선하여 측정할 경우 권선에서 열이 많이 발생하게 되고, 또한 높은 출력의 전력 증폭기가 필요하게 된다. 따라서 현재 대부분의 자성분말 코어는 major B-H loop을 측정하지 않고 dc bias 전류를 인가한 상태에서 LCR미터를 사용하여 인덕턴스를 측정하고, 이 인덕턴스로부 터 투자율을 계산하는 방식으로 minor B-H loop을 측정하고 있다.

본 연구에서 자성분말코어의 major B-H loop을 측정 할 수 있는 장치를 제작하기 위해서 2 가지 문제를 극복하려고 하였다. 첫 번째는 최대 전류가 수 백 Ampere 까지 공급이 가능한 전력 증폭기가 있어야 하고, 두 번째는 교류자화 과 정에서 수백 Ampere의 전류에 의하여 코어에 권선된 코일에 서 발생되는 열을 최소화할 수 있는 방법에 대해서 연구를 하고 측정 장치를 제작하였다.

\section{II. 측정장치의 제작}

서론에서 언급한 바와 같이 자성분말 코어의 major B-H loop 측정을 위하여 최대 전압이 $120 \mathrm{~V}_{\mathrm{p}}$, 최대 전류가 100 $\mathrm{A}_{\mathrm{p}}$ 까지 가능한 전력증폭기(AE Techron model 7548)을 사용 하였다. 그리고 토로이드 코어에 권선되는 코일에 의하여 발 생되는 열을 최소화하기 위해서는 측정 시간을 단축시켜서, 코어의 권선에서 발생 된 열에 의하여 코어에 온도가 올라가 기 전에 측정을 완료하게 하였다. 이를 위하여 자화력 $H$ 의 측정을 위하여 일차 코일에 흐르는 전류를 측정하기 위한 전 류측정용 션트 양단의 전압과, 자속 밀도 $B$ 를 계산하기 위하 여 2차 코일에 유도된 기전력 신호를 디지털로 변환하여 컴 퓨터에서 $B, H$ 신호를 연산을 하는데 실시간으로 하여, 전력 증폭기의 출력을 증가시키면서 측정하고자 하는 최대 자속밀

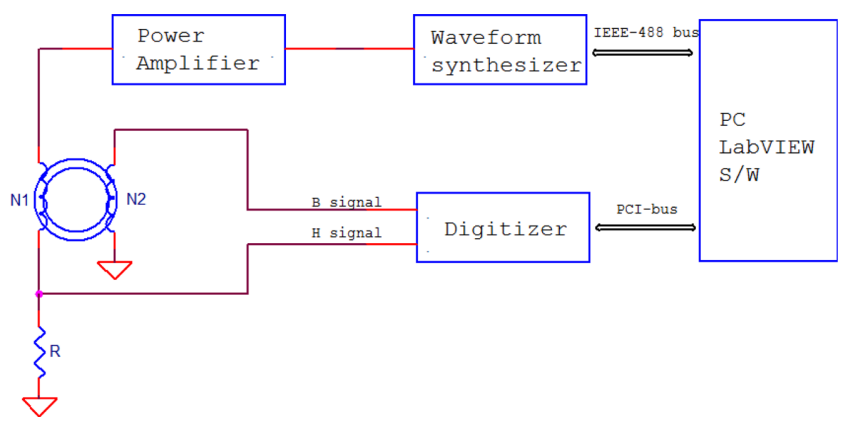

Fig. 1. (Color online) Schematic diagram of the hysteresis loop tracer.
도 $B_{\max }$ 나 최대 자화력 $H_{\max }$ 에 도달하면 측정을 바로 멈출 수 있게 하였다. 혹시 측정 중 최대 자화력이나 최대자속밀 도를 조절하는데 시간이 5 초를 경과하면 증폭기의 출력을 자 동적으로 점진적으로 감소되게 하여 코어의 권선에서 발생하 는 열을 최소화 하였다. Fig. 1은 본 연구에서 제작한 측정 장치의 개략도로 전력 증폭기에 입력되는 교류 전압을 컴퓨 터로 제어하기 위하여 파형 합성기(Agilent Model 3320A)를 사용하였고 PC와는 IEEE-488 interface로 조절할 수 있게 하였다. 한편 션트 저항 $(0.1 \mathrm{Ohm}, 300 \mathrm{Watt})$ 양단에 인가된 전 압과 2차 코일에 유도된 기전력을 $\mathrm{PC}$ 에서 실시간으로 받기 위하여 PCI bus를 사용한 digital oscilloscope용 DAQ(Data AcQuisition: NI PCI 5105)를 사용하였으며 $\mathrm{ADC}$ 의 분해능 은 $12 \mathrm{bit}$ 이였고 최대 샘플링 속도는 $60 \mathrm{MHz}$ 8개의 채널을 동시에 샘플링 할 수 있는 장치였다. 측정 소프트외어는 LabVIEW를 사용하였다. Fig. 2는 본 연구에서 제작한 장치 의 사진으로 왼편의 랙은 $\mathrm{DAQ}$ 가 내장된 $\mathrm{PC}$ 가 장착된 부분 이고 오른편 랙은 아래에서부터 전력증폭기, 시편, B-H 신호 처리 전자장치, 오실로스코프 및 파형합성기가 장착되어 있다.

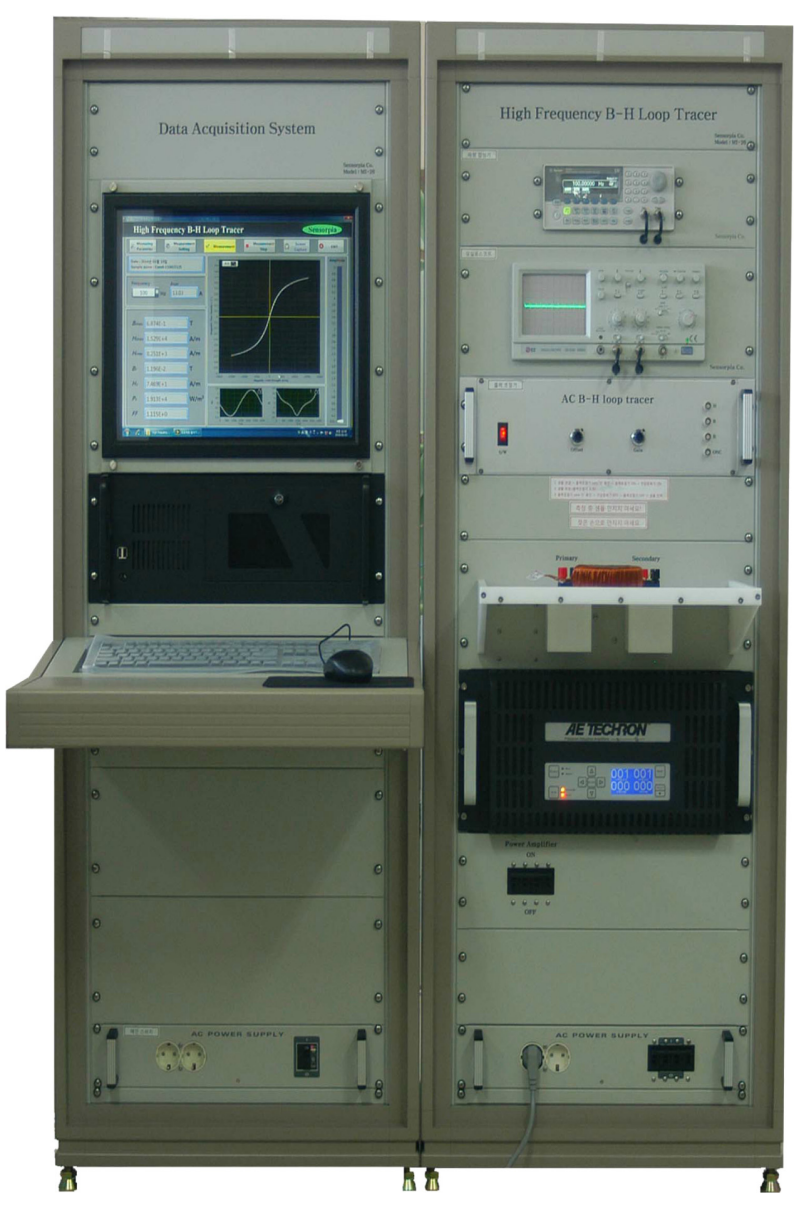

Fig. 2. (Color online) Photography of the constructed hysteresis loop tracer. 


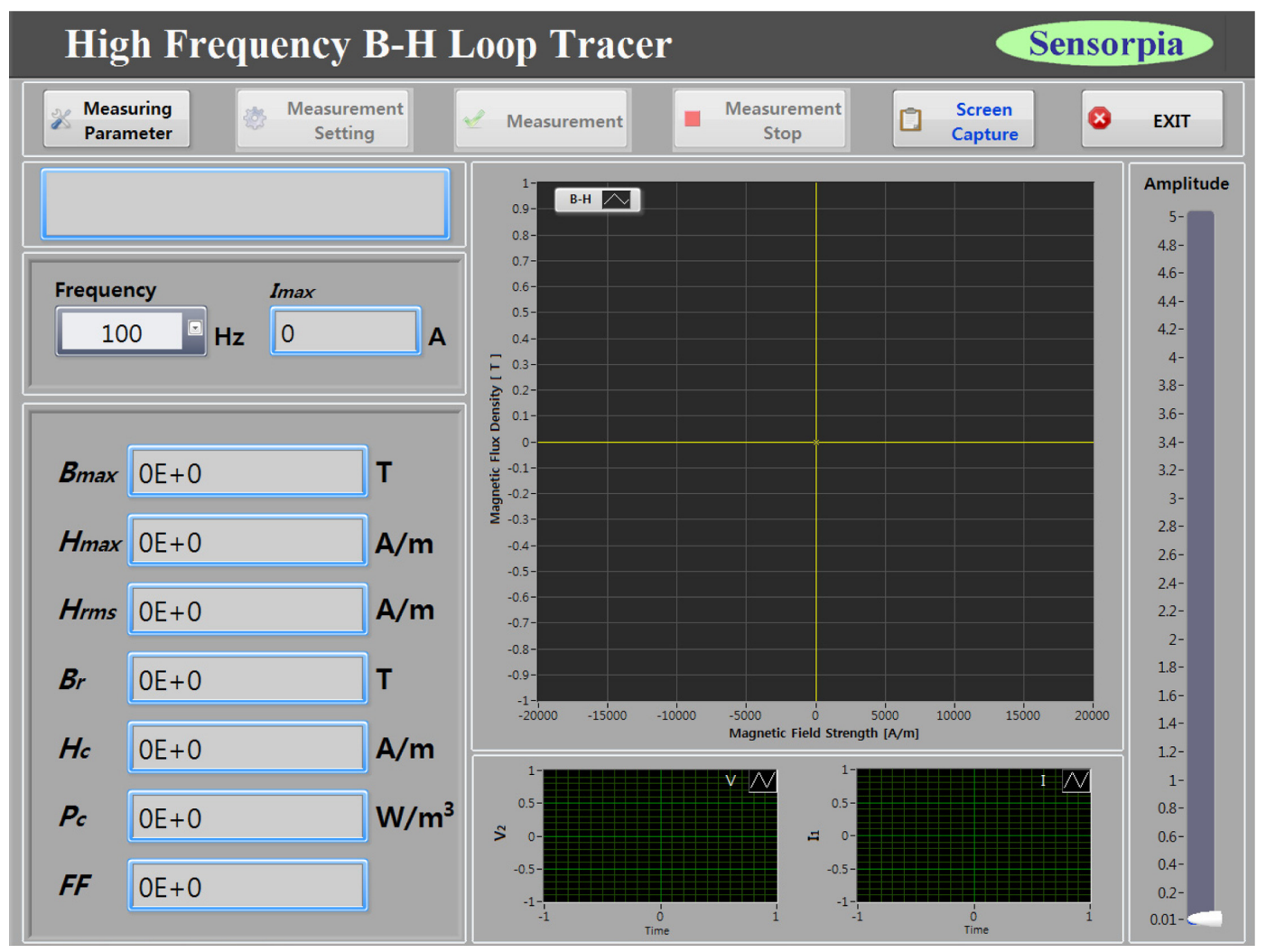

Fig. 3. (Color online) Window of virtual instrument for measuring software.

LabVIEW로 프로그램 한 측정 소프트외어의 가상계측기 (VI: Virtual Instrument)창은 Fig. 3과 같다. 측정하고자 하 는 변수인 측정 주파수, 시편의 내경, 시편의 외경 및 단면적 을 입력 할 수 있게 하였으며, 1 차 코일에 흐르는 전류와 2 차 코일에 유도되는 기전력은 오른편 아래에 오실로스코프와 같이 표시 할 수 있게 하였고 실시간으로 계산되는 자기이력 곡선, 최대 자속밀도 $B_{\max }$ 최대 자화력 $H_{\max }, \mathrm{rms}$ 자화력 $H_{r m s}$, 잔류자속밀도 $B_{r}$, 보자력 $H_{c}$, 철손 $P_{c}$ 및 2 차 코일에 유도된 기전력의 찌그러진 정도로 나타내는 형상인자 $\mathrm{FF}$ (Form Factor $=V_{\text {rms }} / V_{\text {ave }}$ )를 표시 할 수 있게 하였다. 한편 코어에 인가하는 전압의 조절은 소프트외어창의 맨 오른쪽에 있는 scroll bar를 마우스를 이용하여 높이를 조절하면 출력 전압이 조절되게 하였다. 따라서 실제 측정을 할 때, 마우스 를 사용하여 파형 합성기의 전압을 증가 시키면서 측정하고 자 하는 최대 자속밀도 $B_{\max }$ 나 최대 자화력 $H_{\max }$ 에 도달하게 되면, 이때 컴퓨터 키보드의 space bar를 치면 최종 측정값에 서 측정을 중단하고 파형 합성기의 출력 전원은 점진적으로 감소하게 하였다. 이때 측정 중 발생하는 열 문제를 해결하 기 위하여 측정 전류가, $10 \mathrm{~A}$ 이상이 되면 경고창이 뜨고 5 초가 경과하면 자동적으로 측정을 중단하고 파형합성기의 출 력 전압을 점진적으로 감소시키게 하였다.

\section{III. 측 정}

토로이드 형태의 자성분말합금코어는 2 개의 코어를 택하였

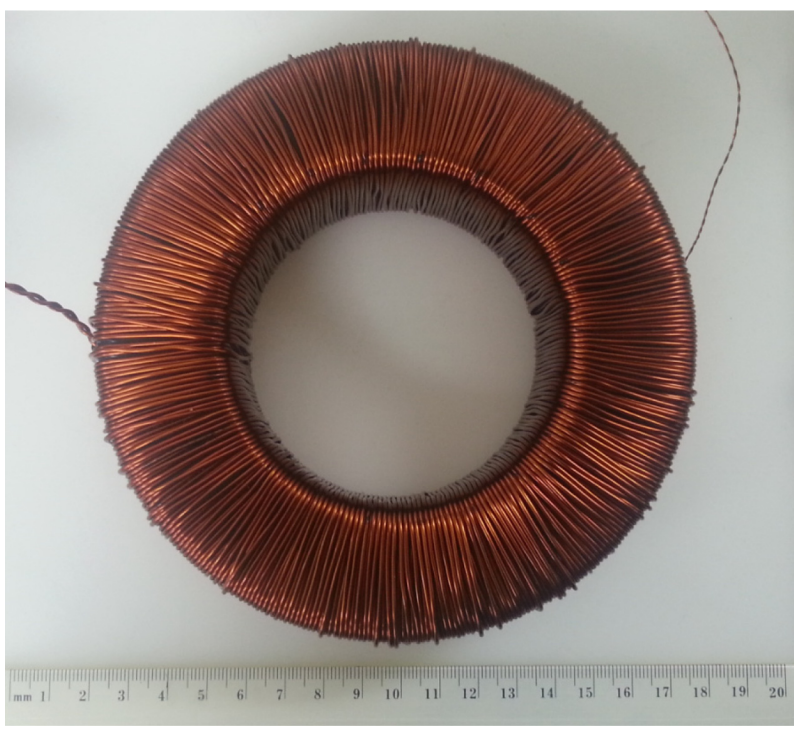

Fig. 4. (Color online) Photography of the coil wound metallic powder core; dimension of core (OD: $134 \mathrm{~mm}$, ID: $77 \mathrm{~mm}$, height: $42 \mathrm{~mm}$ ), $N_{1}=401$ turns, $N_{2}=5$ turns. 


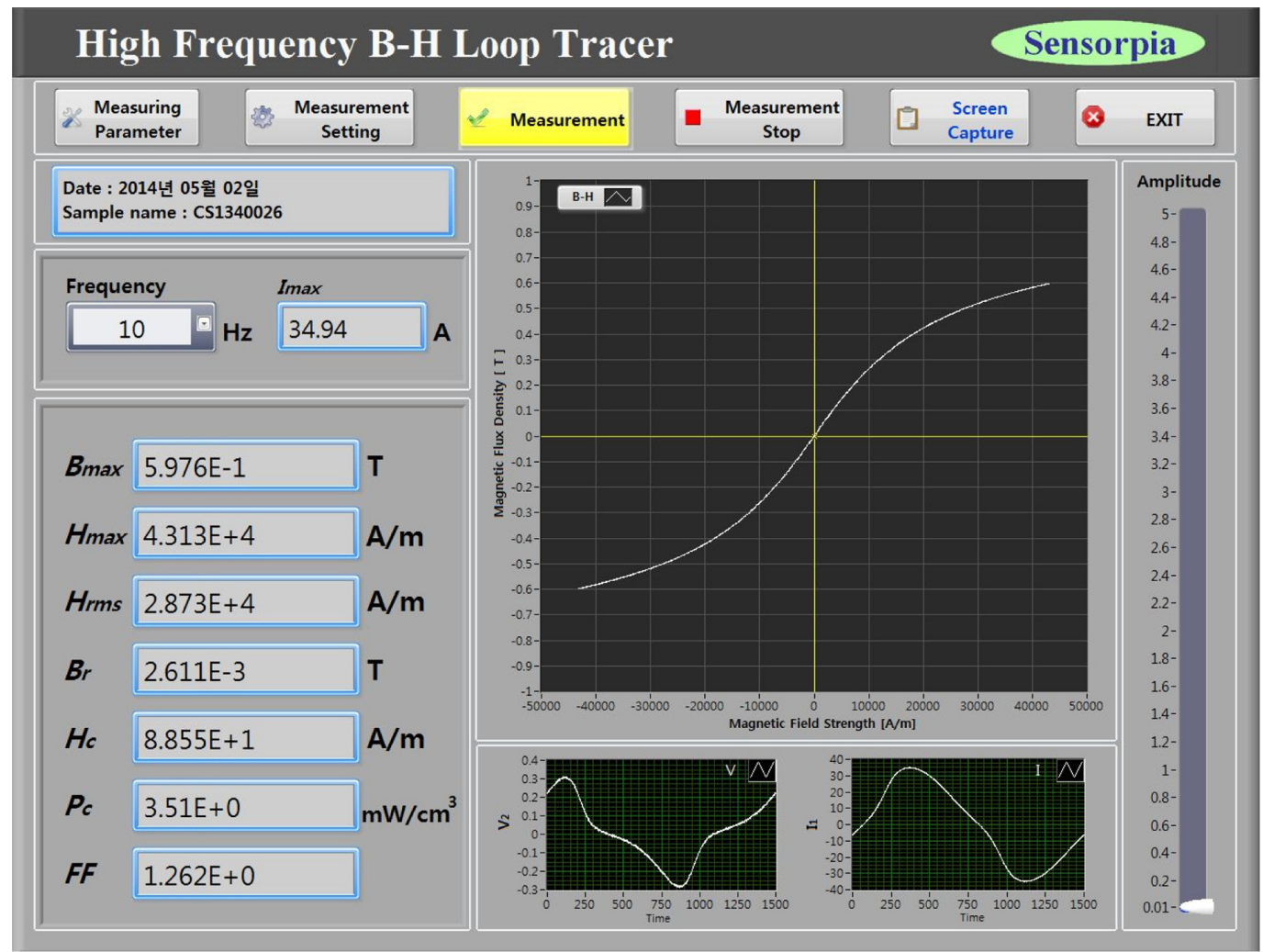

Fig. 5. (Color online) Measured VI window for the coil wound metallic powder core of Fig. 4.

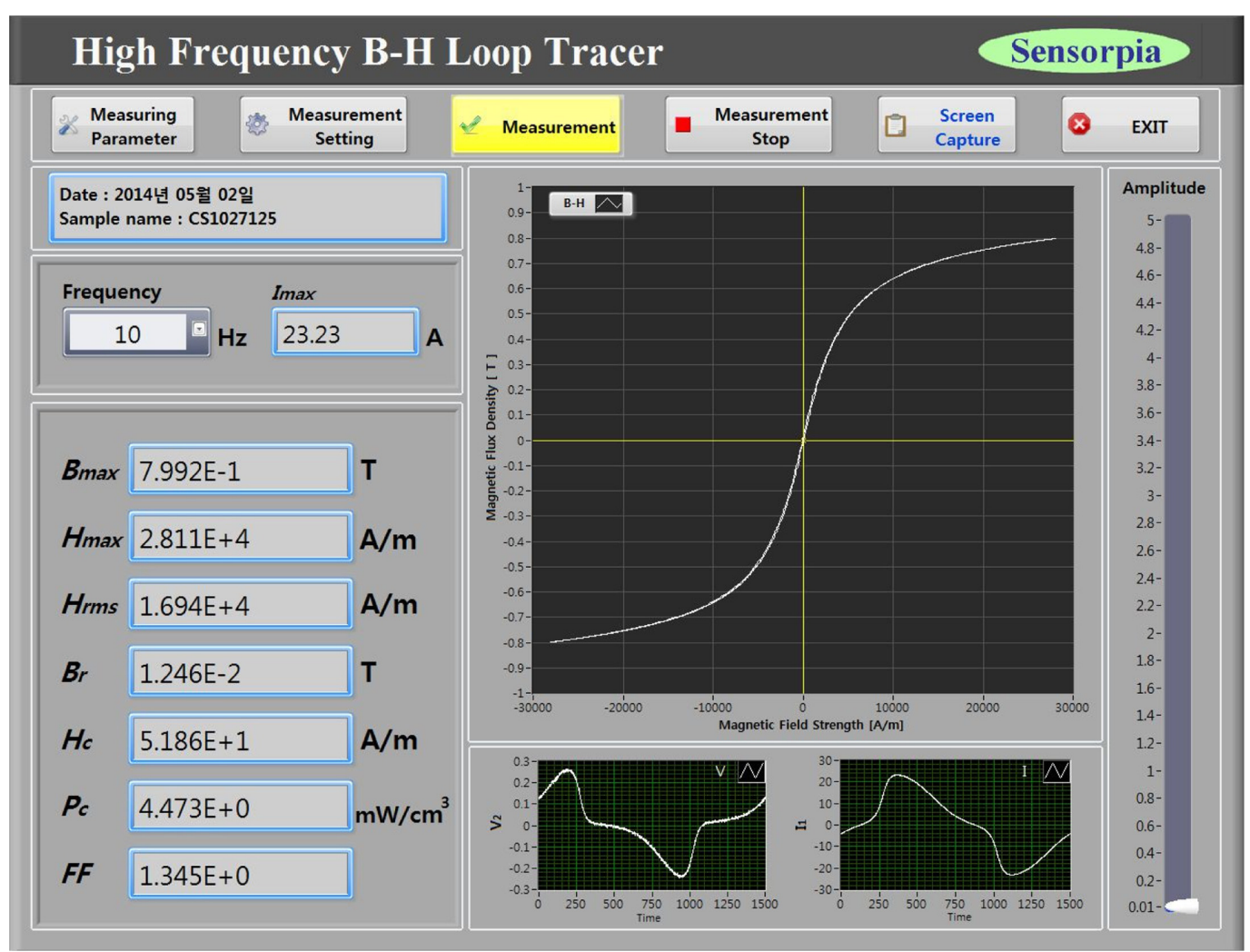

Fig. 6. (Color online) Measured VI window for the coil wound metallic powder core; dimension of core (OD: $103 \mathrm{~mm}, \mathrm{ID}: 55.7 \mathrm{~mm}$, height: $28.5 \mathrm{~mm}$ ), $N_{1}=294$ turns, $N_{2}=5$ turns. 
다. 1 개는 상대 투자율이 125 정도이고 포화 자속밀도에 도 달하는 자화력이 $20 \mathrm{kA} / \mathrm{m}$ 정도인 코어와 또 다른 한 개의 코어는 상대 투자율은 26 정도이고 포화 자속밀도에 도달하 는 자화력이 $50 \mathrm{kA} / \mathrm{m}$ 인 분말코어를 선택하였다. Fig. 4의 사 진은 자화력이 $50 \mathrm{kA} / \mathrm{m}$ 정도에서 코어가 포화가 되는 코어 로 외경이 $134 \mathrm{~mm}$, 내경이 $77 \mathrm{~mm}$ 높이가 $42 \mathrm{~mm}$ 인 자성분 말코어에 일차 코일은 직경이 $1 \mathrm{~mm}$ 인 에나멜 동선을 401 회 권선하였으며, 2차 코일은 직경이 $0.3 \mathrm{~mm}$ 인 에나멜 동선 을 5 회 권선을 한 것이다. Fig. 5 는 이 코어를 제작한 B-H loop tracer에 연결하여 측정주파수 $10 \mathrm{~Hz}$ 에서 측정 결과이다. Fig. 5에서 보면 최대자속밀도를 0.6 T까지 자화를 시키기 위 하여 $35 \mathrm{~A}$ 의 전류를 인가하였으며, 이때 최대 자화력이 43 $\mathrm{kA} / \mathrm{m}$ 이였다. 한편 자화력이 $20 \mathrm{kA} / \mathrm{m}$ 정도에서 포화가 되는 코어의 경우 코어로 외경이 $103 \mathrm{~mm}$, 내경이 $55.7 \mathrm{~mm}$ 높이 가 $28.5 \mathrm{~mm}$ 인 자성분말코어에 일차 코일은 직경이 $1 \mathrm{~mm}$ 인 에나멜 동선을 294회 권선하였으며, 2차 코일은 직경이 0.3 $\mathrm{mm}$ 인 에나멜 동선을 5 회 권선을 한 것이다. 측정 결과는 Fig. 6과 같이 최대자속밀도를 $0.8 \mathrm{~T}$ 까지 자화를 시키기 위하 여 $23 \mathrm{~A}$ 의 전류를 인가하였으며, 이때 최대 자화력이 $28 \mathrm{kA} /$ $\mathrm{m}$ 이였다.

\section{IV. 결 론}

토로이드 형태의 자성분말합금 코어의 경우 major B-H loop을 측정하기 위해서는 높은 자화력이 필요로 하여, 일반 적으로 $\mathrm{dc}$ bias 전류하에서 인덕턴스를 측정하는 방법이 많 이 사용 되었다. 그러나 본 연구에서는 major B-H loop을 직접 측정할 수 있는 장치를 설계 제작하고, 그 성능을 측정 하여 보았다. 토로이드 형태의 자성분말 합금코어를 포화 자 화시키기 위해서는 수십 $\mathrm{kA} / \mathrm{m}$ 이상의 자화력을 인가 할 수
있어야 되기 때문에, 이를 얻기 위하여 최대 전류가 $100 \mathrm{~A}_{\mathrm{P}}$ 인 전력 증폭기와 측정 시간 중에 높은 전류에 의하여 코일 권선에서 발생하는 열 문제를 해결하기 위하여 실시간으로 자 기 이력 곡선을 측정 할 수 있게 실시간으로 B-H 신호를 디 지털신호로 변환하여 컴퓨터 소프트외어에서 자속밀도 $B$ 와 자화력 $H$ 값을 계산하고, 이 값들로 부터 주요 자기 특성인 최대자속밀도 $B_{\max }$, 최대 자화력 $H_{\max }$, 보자력 $H_{c}$, 잔류자속 밀도 $B_{r}$ 및 형상인자 $(\mathrm{FF})$ 를 계산하여 가상계측기 $(\mathrm{VI})$ 창으로 표시 할 수 있게 하였다. 예를 들면 자화주파수 $10 \mathrm{~Hz}$ 에서는 매초 10 번의 자기 이력 곡선을 실시간으로 $\mathrm{VI}$ 창에 표시 할 수 있게 하였다. 제작된 장치를 이용하여 외경이 $134 \mathrm{~mm}$, 내경이 $77 \mathrm{~mm}$, 높이가 $42 \mathrm{~mm}$ 인 자성분말코어에 일차 코일 을 직경이 $1 \mathrm{~mm}$ 인 에나멜 동선을 401회 권선하고 이차 코 일을 직경이 $0.2 \mathrm{~mm}$ 인 에나멜 동선 5 회 권선하여 측정을 하 여 본 결과 최대 인가 자기장을 $43 \mathrm{kA} / \mathrm{m}$ 까지 인가 할 수 있었다.

\section{감사의 글}

본 연구개발을 위하여 2014년 한남대학교 학술연구조성비 에 의하여 일부 지원되었으며, 이에 감사드립니다.

\section{Referecnes}

[1] IEC 60404-6 "Method of Measurement of the Magnetic Properties of Magnetically Soft Metallic and Powder Materials at Frequencies in the Range $20 \mathrm{~Hz}$ to $200 \mathrm{kHZ}$ " (2003).

[2] ASTM A 596, "Test Method for Direct-Current Magnetic Properties of Materials Using the Ballistic Method and ring Specimens" (1999). 